\title{
NEW BIOLOGY BUILDING OF THE UNIVERSITY COLLEGE OF WALES, ABERYSTWYTH
}

\begin{abstract}
A NEW Biology Building to accommodate the Departments of Botany and Zoology of the University College of Wales was officially oponed by Sir Keith Murray, chairman of the University Grants Committee, at Aberystwyth on April 27.

The Departments of Botany and Zoology had been housed for many years in old-fashioned buildings too small for their needs, so that a move to new quarters was eminently desirable. The new building which now contains these Departments is situated on a hill behind the town, with an excellent view over Cardigan Bay, on the new College site, an area of former farmland which is large enough to take as many new buildings as the College is likely to neod in the fore-
\end{abstract}

these classes are excellently 6quipped for general boíanical work. Thero aro also special laboratories for the honours students and for advanced classes in plant physiology. Preparation rooms have boen provided on each floor, to serve these laboratories. The botany lecture room eccommodates 100 students, and there is a seminar room which is also used as a herbarium.

Specially equipped rooms for teaching and research in mycology, and a general research laboratory, are located on the second floor. The ground floor is allocated to plant physiology and biochemistry, and includes the laboratory for advanced classes in this subject, and several research laboratories. There

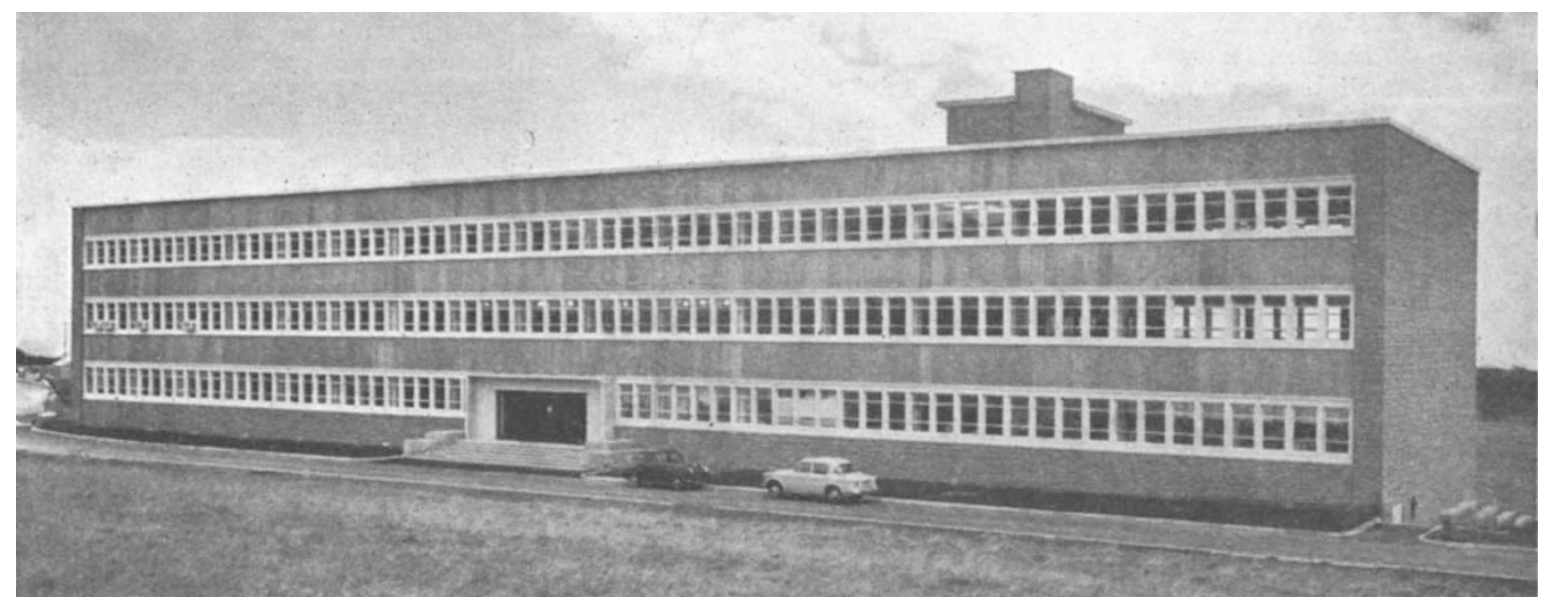

Fig. 1. The Biology Building at the University College of Wales, Aberystwyth

seeable future. The Biology Building is the third one to be erected on this site, the others being a men's hostel and the Institute of Rural Science. The College therefore now has a nucleus of a 'campus' about half a mile from the town. The architects for all these buildings were Sir Percy Thomas and Son, Cardiff.

In general plan the building consists of four floors, with a large lecture theatre projecting towards the sea from the middle of the lowest floor. The Botany Department has the north end of each of the four floors, the Zoology Department the south end.

Rooms shared by the two Departments are situated in the centre of the building; this applies to the joint library and staff common room on the first floor. The joint lecture theatre seats 190 and is provided with a projection room and modorn equipmont for showing sound films and colour transparencies. The present number of students in each of the Departments is about 150.

The planning and design of the new Botany Depart. ment was carried out by Prof. Lily Newton, in consultation with the architects and staff. Special attention was given to the provision of adequate teaching laboratories for the second-and third-year classes, and the two large laboratories provided for are special facilities for enzymology, the use of radioactive materials and work on plant hormones. Four large growth rooms, with controlled lighting, tompera. ture and humidity, provide facilities for controlled environment studies. All the physiological laboratories are served with water, gas, electricity and vacuum lines. The accommodation in the basement includes photographic dark rooms, workshop and a laboratory specially equipped for algological work.

In the old building, many lines of research were severely handicapped through shortage of space, poor services and inadequate equipment. The greatly extended accommodation and facilities, and the provision of a considerable amount of modern scientific equipment in the new Department, now meet the requirements for present-day botanical research.

The Zoology Department has been planned on the principle that in a small, rathor remote situation it is better to make reasonable provision for several aspects of a subject than to make comprehonsive provision for any one particular line of teaching or research at the expense of the others. The Department is therefore equipped to teach comparative anatomy, physiology and embryology, together with genetics and ecology: and for students who reach 
the honours or postgraduate levels it also teaches entomology, parasitology and marine biology. If there is any special emphasis in the equipment provided, it is in the direction of ensuring that adequate arrangoments exist for teaching and research in the field of comparative physiology, because the future of zoology is so much bound up with this that no department can expect to contribute substantially to the progress of the subject unless it is well equipped
for such work.

The various rooms in the Department (about sixty) are so arranged that the circulation of large numbers of students is confined in the main to the two lowor floors, with the result that senior students and staff have the two upper floors to themselves. Thus the large locture theatre opens from the basement, and the main students' cloakrooms are on the same level. On the floor above is the large laboratory, with the zoology lecture room opening from the same passage. The floor next above this one is laid out primarily for senior physiological teaching and research, and also has a technicians' common room, a larger common room for the academic staff, and the library. The top floor provides private rooms for the staff and for postgraduate research, as well as the honours laboratory with an adjacent room for section-cutting.

Several other principles have been kept in mind during the planning. Plenty of store-rooms have been provided, and also an adequate number of photographic dark-rooms situated on different floors, so that technicians, research students and academic staff do not need to use the same ones. Further, the teaching laboratories have been supplied with large and well-equipped preparation rooms opening into them, and this much facilitates the handling of teiaching material. In connexion with the physiological section of the Department there is an aquarium in which various types of work can be done, and this room has a circulation of sea water through six small tank; and a circulation of fresh water through six others. In the basement there is a museum, and an innovation on the same floor. is a visitors' research laboratory in which are four cubicles, each of which can be used by a visiting scientist, as well as general facilities which visitors can share. There are also two constant-temperature rooms : and compressed air is laid on throughout the building. A laboratory properly equipped for the use of radioactive materials has been provided on the roof.

The whole planning of the internal detail of the Zoology Department was done, in consultation with the architects and the staff, by Prof. and Mrs. T. A. Stephenson.

Aberystwyth is in many ways very favourably situated for biological studies, since there are close at hand a wide variety of habitats, which include not only the sea and shore for marine studies, but also inland rivers and lakes, woodlands, bogs, moorland, sand-dunes and salt-marsh. Moreover, there is a large botany garden very close to the new building. In the past the Biological Departments wore handicapped by inadequate laboratory accommodation ; but with the large new laboratories and the close proximity of a wide variety of natural vegetation and fauna, the College can now offer opportunities for biological teaching and research which compare favourably with those provided elsewhere in the United Kingdom.

\section{T. A. STEPHENSON}

P. F. WAREINC:

\section{BOUNDARY-LAYER RESEARCH IN FLUIDS}

$\mathrm{W}$ HEN a body of streamlined shape moves through a fluid, the latter is disturbed, but in the main it is not carried along with the body. On the surface of the body, however, the fluid shares the body's motion, because viscosity prevents any slip occurring. The change in speed between the fluid at the surface adhering to it and the fluid in the external flow takes place in a thin layer, called the boundary layer. Boundary-layer flow has been intensively studied because many important practical effects depend on the nature of this flow. The fluid exerts a frictional retarding force on the body. This drag depends on the way in which the fluid speed varies across the boundary layer, and it tends to decrease as the boundary-layer thickness increases. It is increased if the flow in the boundary layer, instead of being completely smooth or laminar, is turbulent, with a small-scale eddying motion superimposed on the mean motion. Much work has therefore been devoted to the conditions which provoke the transition from laminar to turbulent flow in the boundary layer.

Another important practical problem is boundarylayer separation. Relative to the body, the boundary layer fluid has less momentum than that in the external flow. Hence if over the surface of the body the pressure rises in the stream direction, the bound. ary-layer fluid may be brought to rest, because it will tend to be retarded relatively more by the pressure gradients than the fluid in the external flow. A piling-up of low-speed fluid near the surface may therefore occur, which may make the streamlines in the external flow depart markedly from the shape of the body. A low-pressure region over the rear end of the body sometimes results, with a consequent large pressure-drag. Here again turbulent boundary layers behave very differently from laminar ones, being much less prone to separation. In recent years, with the advent of high-speed aircraft and missiles, aerodynamic heating has become of great importance. This is largely a boundary-layer effect, because it is mainly due to the kinetic energy of the free-stream air being converted into heat when, relative to the body, the air is slowed down by friction inside the boundary layer. Associated with their greater frictional drag, turbulent boundary layers tend to produce greater rates of heating than laminar ones.

It can be understood from the foregoing that the study of boundary layers as a special department of fluid mechanics has itself become specialized into several sub-departments. These specialist interests are exemplified by the papers presented at the meeting on "Boundary Layer Research" arranged by Dr. W. P. Jones of the Aerodynamies Division, National Physical Laboratory, on behalf of the N.A.T.O. Advisory Group for Aeronautical Research and Development and held in London during April 25-29. The topics discussed were grouped under the following headings: (1) effects of roughness on boundary-layer stability; (2) boundary-layer con- 